\title{
Analysis on the EAP Reading Text Materials Based on Schema Theory Du Xuejuan
}

\author{
Suzhou Art\& Design Technology Institute
}

hunter2011@foxmail.com

Keywords: Schema Theory; EAP; Reading materials; Selection of materials

\begin{abstract}
EAP can also be called academic English. EAP reading materials are important tools to cultivate and improve students' reading ability as well as a model to improve students' academic communication ability. Relevant documents indicate that the current EAP, namely the academic English reading material, has many problems and deficiencies. However, EAP reading materials with good quality can effectively compensate for the lack of EAP teaching experience of college teachers, help teachers organize the classroom teaching well; it can also improve the students' English reading interest and English communication ability in their academic field so that it can improve students' comprehensive academic ability to the full extent. This paper studies the common deficiencies of Chinese EAP materials and analyzes it based on the relevant text editing theory and reading studies and makes in-depth investigation for the selection of EAP reading materials based on Schema Theory.
\end{abstract}

\section{Introduction}

EAP reading materials can improve reading ability to some extent; reading materials can effectively stimulate the inspiration of classroom language activities, improve students' confidence in learning professional English and improve their subjectivity for learning special academic English. Generally speaking, reading materials for traditional non-English major are irrelevant to the related academic content; therefore, most non-English major students are not familiar with some academic words and lack of understanding for academic styles, which leads to the obstacles during the academic communication in English. College English academic writing and the oral communication of academic English should base on reading materials. Since most college teachers put their emphasis on teaching and have limited understanding for relevant majors; they have difficulty in selecting EAP reading materials, such as the lack of resources. Therefore, they prefer to select college English text during teaching. Hence, proper and effect EAP reading materials are of great importance for the teaching of college English.

\section{Analysis on demands}

One of the criteria for successfully selection of college English text is whether the text can satisfy the learning demands of college students. Therefore, the demand analysis should be done before editing the English text. Editing of a Standard English text is careful and hard. Firstly, it should analyze the demand of objective groups during the Standard English learning which should involve the EAP and reading materials of special English, which should be "teachers-oriented" and combine with the mental demands and interests demands of students; secondly; the texts should conform to the demands of development of era. The types and contents of the EAP reading materials should be diversified and involve into the actual materials, which has some realistic effect for working after graduation.

The main contents of demand analysis include the collection and evaluation of relevant skills of English courses design, while the concrete content is to investigate the learning objectives and relevant background of learning objectives; then consult the requirements of relevant courses and academic tasks to college teachers. Apart from this, it should have clear understanding of students' English language skills and background knowledge before editing EAP reading materials; then 
select proper reading objectives based on students' reading skills and basis condition of language application.

\section{Enlightenments of Schema Theory on selection of EAP reading materials}

The difficulty of English reading text can affect the success of editing English materials to some extent. According to a lot of practice, it indicates that the application of specially-used English texts in China have the following problems: 1) improper of difficulty in English reading materials and there is no relevant note for some English terms; the English reading materials are too difficult for students that surpasses the students' knowledge scope, which cannot fully represent the relevant principles of step-by-step or increasing of difficulty for English reading materials; 2) some English reading texts are too simple which only adds the ordinary English with terms; therefore, students can only learn some terms. So it is necessary to analyze and discuss the difficulty for English reading texts if you want to strictly grasp the difficulty of EAP reading materials. Generally speaking, the traditional opinion regards that the factors affecting the difficulty of English reading materials lie in the English grammar, vocabulary etc. However, Schema Theory holds the opinion that the comprehension of English texts depends on the readers' background knowledge and final affecting factors include English language, texts and length etc.

Language Schema. Language schema consists of English knowledge and the ability of using English. Relevant documents indicate that as for learners of EAP reading, the difficulty of vocabulary lies in the general academic vocabulary between ordinary words and highly difficult academic words of the disciplines. Relevant studies indicate EAP reading text increases rich consents and language schema. Therefore, EAP reading materials can edit the two or three reading materials with same topic together during the selection so that it can improve the recurrence rate of relevant English vocabulary to some extent, which is convenient for the learning of learners. But generally speaking, if it only relies on the repetition of vocabulary to help students learning academic vocabulary during the selection of EAP reading text, it is hard to achieve satisfactory results. Therefore, it is necessary to teach directly during English teaching so that it can effectively help students learn application and concrete usage of a word in concrete context.

Content Schema. Content Schema consists of the previous English experience and relevant background knowledge of learners. Generally speaking, the more the relevant content schema of English reading materials the learners have, the better the learners' reading comprehension, information storage and recalling of information. During learning the EAP reading materials, there is always difficulty in understanding the English academic reading for content schema. The reasons mainly lie in: 1) learners of EAP reading materials do not understand or do not familiar with relevant academic content; 2) learners of EAP reading materials have relevant schema but do not timely actively or effectively activate it. Therefore, staff for editing EAP reading materials should help students establish and activate content schema.

In practical usage, however, some EAP reading materials in China put too much emphasis on the relevant academic content, which makes the whole chapters of the reading text select from the original English document and lack of the editing of original English based on the actual English level of students, thus leading to the bad combination of EAP reading materials and academic knowledge and language training. In actual teaching, some reading in English text puts much emphasis on the introduction of background knowledge while ignores the core theory and development of English. Therefore, during the editing of EAP reading materials, methods such as introducing main content, questions discussion and pre-reading can be applied to help students be familiar with and grasp the learning content and subjects and constantly build up and activate the content schema of learners' thinking. Before the main passage of English reading material, it is necessary to introduce the main contents of the text to the learners, which can help learners recall the learned schema. Apart from this, some relevant topics can be set before the main passage which can result in discussion of learners, which can activate the students' content schema to some extent. In order to remarkably improve learners' reading interest and reading effect, Chinese forms can be applied during editing the EAP reading materials to present the pre-reading materials. The selection 
of materials should fully consider the forms and diversity of materials. The main reason lies in that the diverse reading materials can better attract and be more interesting to the learners, thus better activating the subjectivity of learners.

Formal Schema. Formal schema mainly consists of the structure of English reading passage, which refers to the styles, framework and structures of English reading materials. One of the purposes for academic reading teaching is to help students understand and grasp academic passages and structures of different styles. Since the academic texts have many styles, the staff for editing EAP reading materials should emphasize the coverage of academic passages and select the texts which adapt to the comprehension ability of students strictly based on the major features of students. During this process, the selected texts should embrace essential contents of different academic courses and deal with the styles, lengths and completion of English reading chapters. Apart from this, EAP reading teaching should cultivate the consciousness of course structures and the reason lies in that the grasp of course structures can help students grasp the thoughts of original authors to much extent and have a deep understanding and grasp of the organizational structures of English reading texts. However, since many specially-used English texts in China put much emphasis on the written text and only trains the learns language skills from reading, translation and vocabularies. Therefore, editors of EAP reading materials should distribute properly the proportion of academic speech, academic report and so on during the selection of courses and properly design the relevant oral exercises to improve the comprehension of texts by students, which can better cultivate student's oral academic communication ability.

Strategy Schema. Reading strategy mainly consists of the inspection behaviors of students for their own reading comprehension during reading the passage. Currently, the main problem in the texts of English majors in Chinese universities is that it lacks the professional editing for the EAP reading materials and lacks of some context, and the EAP reading text puts much emphasis on the usage of language instead of the context of language, therefore, it cannot effectively cultivate the pragmatic ability of students. Apart from that, the English reading text in China puts much emphasis on the comprehension of English text; the tasks for training mainly testify the comprehension of learners, which includes selection, filling in blanks and judging true or false. Therefore, the selection of EAP reading materials should fully emphasize the learners' strategic consciousness and cultivation of relevant ability.

\section{Conclusion}

Since learners of EAP reading texts in China are different in language ability, knowledge background and other aspects, the EAP reading texts are not ideal in all the teaching. In order to reach ideal EAP reading text, it should emphasize the communication and feedbacks between English teachers and students. English teachers should accurately understand and grasp the language ability and relevant background knowledge. The selection of EAP reading materials should fully use the existing materials and edit and revise the selected materials for many times by group editing. Only by scientific analysis, comprehensive study, innovation, can editors for EAP reading materials edit satisfactory academic English reading materials in the selection of materials. In teaching practices, teachers should adjust according to the real conditions of students and timely update so that they can achieve optimal teaching effect.

\section{References}

[1] H. Liu. Research on the Selection of EAP Reading Text under Schema Theory. Foreign Languages Research, 2014,17(3):52-56.

[2] H. Liu. Enlightments of Foreign EAP Reading Demands on EAP Reading Teaching in China. Foreign Languages Research, 2015,26(2):56-59.

[3] B. Li. Application of Business Text Reading Teaching of Schema Theory--Taking the Business English Reading Teaching as an Example. Education Exploration, 2012,11(2):45-46. 
[4] W. Cao \& Z.Y. He. Study on the Rules and Combination Features of Single Syllable Abbreviation and Combinations from Image Schema Theory. Journal of Suzhou University (Philosophy and Social Science. 2012,33(4):12-15.

[5] Q. Si. \& M.L. Li. Study on the Mental Process of Reading Comprehension from the Perspectives of Schema Theory. Journal of Inner Mongolia Normal University (Humanity and Social Science Edition), 2012,39(1):96-99.

[6] Y. Li. Englightements of Schema Theory on Teaching of College English Reading. Journal of Taiyuan City Vocational and Technical College. 2010,22(5):130-131.

[7] L.M. Zheng. On Schema Theory and English Reading Materials. Journal of Shenyang College of Education, 2012,9(6):52-54.

[8] Y.H. Chen. Analysis on the Schema Theory in the Teachig of Junior English Reading. Language Sch learning Newsroom (Middle School Edition, Ten-days Periodic). 2013,11(7):40-41. 